\title{
Relative expression of wild-type and activated Ki-ras 2 oncogene in colorectal carcinomas
}

\author{
A. KOTSINAS ${ }^{1,2}$, D.A. SPANDIDOS ${ }^{1,3}$, P. ROMANOWSKI ${ }^{2}$ and A.H. WYLLIE $^{2}$ \\ ${ }^{1}$ Institute of Biological Research and Biotechnology, National Hellenic Research Foundation, 48 Vas. Constantinou Averue, \\ Athens 11635, Greece; ${ }^{2}$ CRC Laboratories, Department of Pathology, University Medical School, Teviot Place, \\ Edinburgh, EH8 9AG, Scotland, UK; ${ }^{3}$ Medical School, University of Crete, Heraklion, Greece \\ Contributed by A.H. Wyllie, September 14, 1993
}

\begin{abstract}
A quantitative, competitive RT-PCR-RFLP assay was developed to detect and discriminate the expression of mutant versus wild-type alleles of the Ki-ras oncogene. The aim was to establish whether these alleles are differentially expressed in human malignant neoplasma, since experiments in vitro have shown stoichiometric representation and expression of ras genes does not necessarily engender a cancer phenotype. Sixteen primary colorectal carcinomas and two colorectal carcinoma xenografts, passed in immunesuppressed mice, were studied. Previous sequence analysis had established that 9 of the primary tumours and both xenografts had codon $12 \mathrm{Ki}$-ras mutations, 4 tumours had codon 13 mutations and 3 were wild-type controls. Wild-type and mutant $\mathrm{Ki}$-ras were co-expressed in all the primary tumours, but the assay showed that stoichiometrically equivalent amounts of the two mRNA species were present in only one-third: in the others, mutant $\mathrm{Ki}$-ras was overexpressed by around $30-60 \%$ relative to wild-type. The xenografts showed a similar range of values, despite their near-total lack of stroma. Ki-ras activation by point mutation is known to be involved in the early, adenoma phase of evolution of colorectal tumorigenesis, but these results show that differential expression of the mutant allele is common in carcinomas and may be associated with persisting growth advantage.
\end{abstract}

\section{Introduction}

Genetic alterations are known to be responsible for cancer. The initiation, progression and promotion of tumours has been associated with a sequence of such genetic aberrations involving oncogenes and oncosuppressor genes $(1,2)$. In human colorectal cancer several of these critically altered genes are known, including APC, MCC, Ki-ras, DCC and p53 $(3,4)$. The alterations in the function of these genes may

Correspondence to: Professor D.A. Spandidos, Institute of Biological Research and Biotechnology, National Hellenic Research Foundation, 48 Vas. Constantinou Avenue, Athens 11635, Greece

Key words: Ki-ras, colorectal cancer, RT-PCR be responsible for specific stages of tumorigenesis and cancer progression (3). Activation of Ki-ras by point mutations at codons 12,13 and 61 appears in the premalignant phase of colorectal tumorigenesis, being observed in the larger (and more dysplastic) adenomas. Carcinomas show the same spectrum of mutations, at approximately the same incidence, around $40-50 \%$.

In a variety of experimental systems, expression of activated ras genes is associated with early stages of carcinogenesis, being apparently responsible for both initiation and progression (1,2,5-8). Recent work, however, has emphasised the importance of gene dosage in the phenotype of cells bearing ras oncogenes (9-11). Whilst the presence of mutated and wild-type ras genes in stoichiometrically equivalent amounts may have little effect on phenotype (12), chemically-induced carcinomas and papillomas of skin frequently differ in that carcinomas tend to have more gene copies of mutated than wild-type ras $(6,9,10)$.

In this study we sought to characterize more fully the role of Ki-ras in human colorectal cancer. In view of reports that ras p21 is less abundant in advanced than in early tumours (22), we asked whether expression of the abnormal Ki-ras oncogene makes a continuing contribution to the development of malignant tumours. We also asked whether wild-type and mutated genes are equally expressed. To do this we developed a competitive RT-PCR-RFLP assay $(13,14)$ using an exon connection strategy in which an antisense primer within exon 3 was coupled with the sense primer in exon 1 already described (15). The exon 3 primer also bore a nucleotide mismatch that created a BstNI site at the 3' end of the PCR product. This controlled for digestion efficiency at a second BstNI site at the 5 ' end of the product, which was destroyed by mutation in codon 12 (Fig. 1).

Using this technique we examined the ratio of expression of wild-type and mutant Ki-ras genes in primary colorectal cancers in man. The results show that mutant $\mathrm{Ki}$-ras, when present, is always expressed, and its expression often exceeds that of wild-type allele.

\section{Materials and methods}

Tumour material. Tumour fragments from colorectal carcinomas were snap frozen in liquid nitrogen after surgery 
and stored at $-70^{\circ} \mathrm{C}$. All tissues were carefully trimmed to remove as much non-neoplastic tissue as possible. A total of 16 colorectal carcinomas were examined, 9 with known codon $12 \mathrm{Ki}$-ras mutations, 4 with codon 13 mutations and 3 without mutation. To control for the effect of non-neoplastic stromal cells on the analysis, two further carcinomas were studied following multiple passage as xenografts in immunesuppressed mice. Although such xenografts faithfully reproduce the histology and genetic defects of the primary tumours (16), they possess little non-neoplastic stroma, which in any case is of murine origin and so affords an inefficient template for the human-specific PCR primers.

Cell lines. Two human colon carcinoma cell lines Colo 320 and SW 480 were employed for quantitative determination of the ratio between normal versus mutant Ki-ras transcripts: Colo 320 cells express only wild-type Ki-ras, whilst SW 480 express only Ki-ras with a codon 12 mutation.

RNA extraction. RNA was extracted by the RNazol B kit (BioGenesis) which is a modified version of the guanidinium isothiocyanate method. In brief, approximately $10 \mathrm{mg}$ of frozen tissue were homogenized in $800 \mu \mathrm{l}$ RNazol B. After addition of $100 \mu \mathrm{l}$ chloroform the mixture was shaken vigorously and centrifuged for $20 \mathrm{mins}$ at $12000 \mathrm{~g}$ at $4^{\circ} \mathrm{C}$. The supernatant was collected and the RNA precipitated with an equal volume of isopropanol. The RNA pellet was washed sequentially with $4 \mathrm{M} \mathrm{LiCl}$ and $75 \%$ ethanol.

The quality and quantity of RNA was assessed by formaldehyde denaturing agarose gel electrophoresis and spectrophotometry at $260 \mathrm{~nm}$ and $280 \mathrm{~nm}$.

cDNA synthesis. $1 \mu \mathrm{g}$ of total RNA was primed with $0.5 \mu \mathrm{g}$ oligo-dT and the reaction was performed in a final volume of $20 \mu 1$ with $200 \mathrm{U}$ MMLV reverse transcriptase (BRL) following the supplier's protocol. After 1 hour at $37^{\circ} \mathrm{C}$ the enzyme was heat inactivated $\left(5 \mathrm{~min}, 98^{\circ} \mathrm{C}\right)$. A negative control without RNA was also included.

PCR amplification. The cDNA was amplified in a $100 \mu \mathrm{l}$ reaction $(10 \mathrm{mM}$ Tris- $\mathrm{HCl} \mathrm{pH} 8.3,50 \mathrm{mM} \mathrm{KCl}, 1.5 \mathrm{mM}$ $\mathrm{MgCl}_{2}, 0.01 \%$ Triton, $200 \mu \mathrm{M}$ dNTPs) with $200 \mathrm{ng}$ of each primer and $2.5 \mathrm{U}$ Taq polymerase (NBL). The amplimer sequences were

5'-ACTGAATATAAACTTGTGGTAGTTGGACCT-3' and 5'-CAAATCACATTTATTTCCTACㅡAGGACCAT-3'. After an extended initial denaturation step $\left(94^{\circ} \mathrm{C}\right.$ for $\left.4 \mathrm{~min}\right)$ the PCR program consisted of $1 \mathrm{~min}$ at $94^{\circ} \mathrm{C}, 1.30 \mathrm{~min}$ at $62^{\circ} \mathrm{C}$ and $1.30 \mathrm{~min}$ at $72^{\circ} \mathrm{C}$ for a total of 25 cycles.

To exclude false positive results due to Ki-ras 1 pseudogene in DNA still present in the RNA preparations, control RNA was subjected to PCR amplification without prior incubation with reverse transcriptase.

PCR amplification for detection of LOH at genomic DNA level was performed as described $(17,18)$.

RFLP analysis. For codon 12 mutations $20 \mu \mathrm{l}$ of the PCR reaction were subjected to BstNI (NEB) digestion (20 U) at a final volume of $30 \mu \mathrm{l}$ at $60^{\circ} \mathrm{C}$ for $3 \mathrm{~h}$. For codon 13 mutations the same procedure was employed as for codon 12 except

\section{A}

\section{$\begin{array}{llll}1 & 2 & 3 & 4\end{array}$}

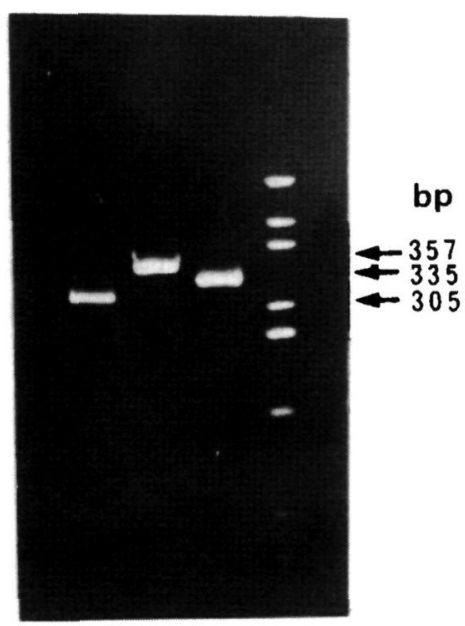

B
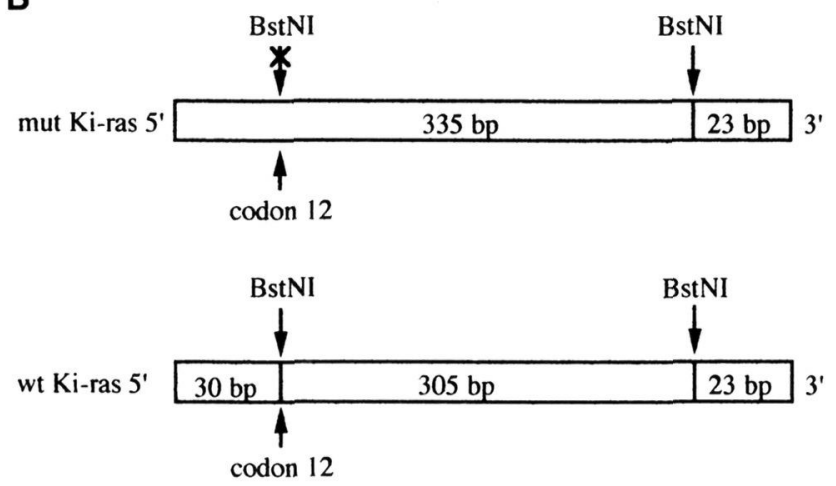

Figure 1. (A) Application of competitive RT-PCR-RFLP on Colo 320 RNA reveals only normal Ki-ras signal being expressed while in SW 480 only codon 12 mutant $\mathrm{Ki}$-ras signal is present. Lane 1: Colo 320, lane 2: undigested PCR product, lane 3: SW 480, lane 4: marker. (B) Nucleotide substitution in the primers facilitate the creation of two BstNI sites. The 3' end site is permanently functional and serves as a control for the efficiency of digestion, discriminating RFLP products from undigested PCR products. The 5 ' end site is functional depending upon the presence of codon 12 mutations.

HphI (NEB) was used at $37^{\circ} \mathrm{C}$. The products were electrophoresed through a $3 \%$ agarose gel (3 parts Nusieve/1 part Seakem). Gels were stained with ethidium bromide and photographed on an ultraviolet light transilluminator.

RFLP analysis for detection of $\mathrm{LOH}$ was performed as described $(17,18)$.

Ratio quantitation. Total RNA from Colo 320 and SW 480 cell lines was mixed in the following mass ratios to create 5 batches of mixtures: $1 / 1,0.5 / 1,0.25 / 1,0.125 / 1,0.0625 / 1$ (Colo 320/SW 480). $3 \mu \mathrm{g}$ of each mixture was used for the RT-PCR-RFLP assay.

The RFLP products were loaded on $6 \%$ mini polyacrylamide gels containing $1 \%$ glycerol. Gels were run in TBE buffer at $100 \mathrm{~V}$ for $1 \mathrm{~h}$. After electrophoresis, gels were stained in ethidium bromide and photographed on a UV 


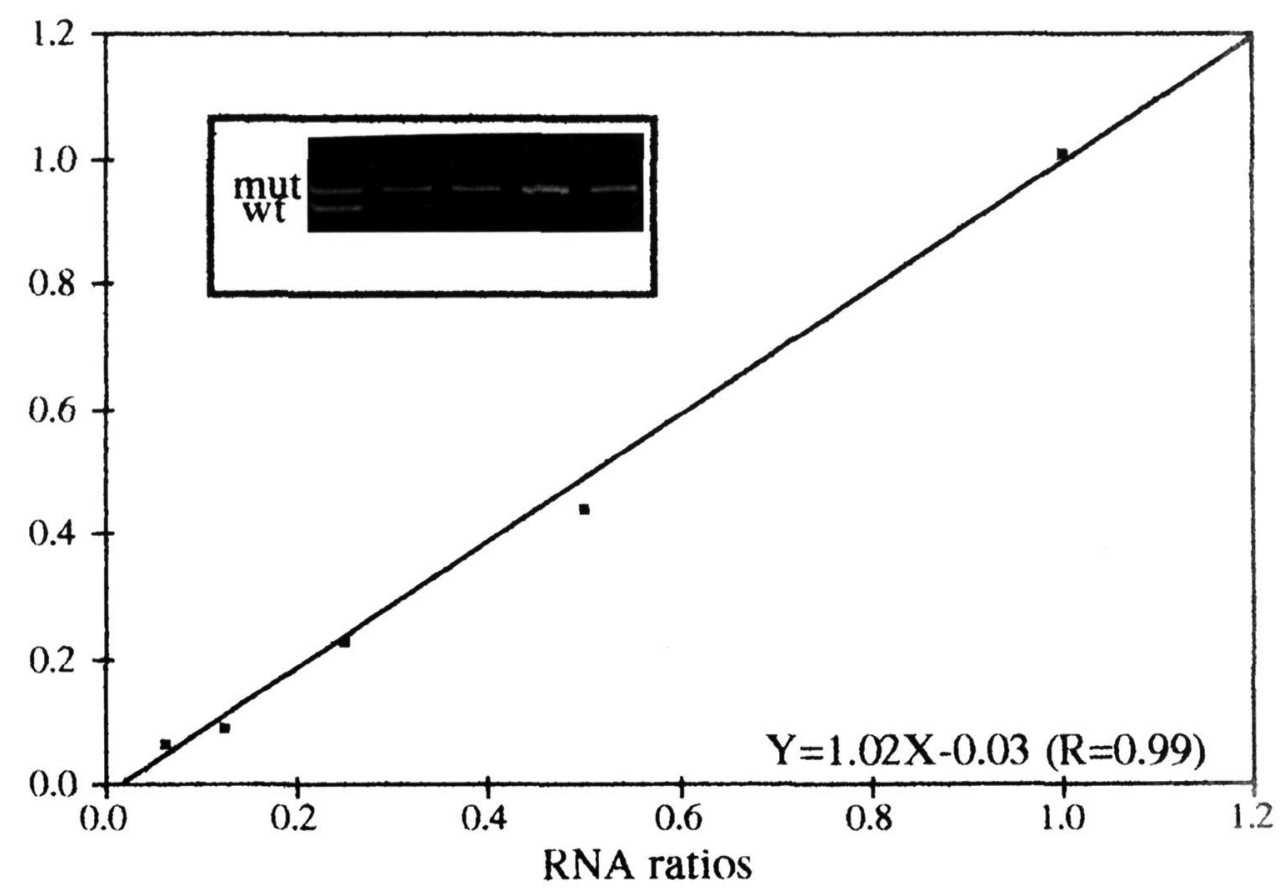

Figure 2. Regression analysis between total RNA ratios of normal versus mutant Ki-ras resulted in a linear relationship described by the equation $\mathrm{Y}=1.02 \mathrm{X}$ 0.03 with a coefficient of correlation $\mathrm{R}=0.99$.

transilluminator. The photographs were scanned on a flatbed scanner (Microteck) and computer image analysis was performed on a Macintosh computer. The densitometric values from computer image analysis were statistically analysed with the aid of Statworks (1.2) on the same computer.

The RFLP products from tumour samples were analysed in the same way. Densitometric values for each tumour taken from two independent experiments, and the average values were used to compute the ratio between the mutant and wildtype Ki-ras transcripts, using the cell line data as a calibration curve.

\section{Results}

Ratio quantitation. To obtain reliable measurements for the ratio of the level of expression between the trasncripts of the $\mathrm{Ki}$-ras locus, we assessed the accuracy of the competitive RT-PCR-RFLP assay, using RNA extracted from the two human colon carcinoma cell lines Colo 320 (wild-type only) and SW 480 (codon 12 mutant only) (Fig. 1). Total RNA from these cell lines was mixed in various ratios, as described in the Methods and competitive RT-PCR-RFLP was performed with various PCR cycles. The ratios of Ki-ras obtained after the RFLP analysis was plotted against the ratios of the initial total RNA from the two cell lines, giving a standard curve (Fig. 2). Under optimum conditions (25 cycles) the data points closely fit a linear equation $(\mathrm{R}=0.99)$. The equation describing this standard curve is $\mathrm{Y}=1.02 \mathrm{X}$ 0.03 , indicating a direct linear proportionality between the input RNAs and the cDNAs amplified from the transcripts. Higher cycle numbers were avoided, however, as this linear relationship was lost, presumably because of the accumulation of heteroduplex products (13).
Codon 12 mutation analysis. All 9 carcinomas with codon 12 mutation expressed both mutated and wild-type Ki-ras transcripts (Fig. 3A). Densitometric analysis of the samples showed that the ratio of mutated and wild-type transcripts was close to unity $(0.8-1.0)$ in only 3 (Table I). In all others, mutant $\mathrm{Ki}$-ras was overexpressed relative to wild-type by 30 $60 \%$. All these ratios of wild-type to mutant Ki-ras cDNA observed in the carcinomas fall within the range shown to be linearly related to transcript in Fig. 2.

Codon 13 mutation analysis. All 4 cases with codon 13 mutation had the same Asp 13 mutation in the genomic DNA. This mutation creates a recognition site for the HphI restriction enzyme which is unique in the amplified cDNA fragment. Hence, cDNA mutant from transcripts is digested with this enzyme while wild-type cDNA is not affected.

Analysis of the 4 carcinomas with Asp13 mutation revealed that both mutant and wild-type transcripts were expressed in all (Fig. 3C). Because of the lack of a second restriction site in the PCR product, the efficiency of digestion with the HphI cannot be controlled. For this reason we did not attempt to quantify the ratio between the Ki-ras transcripts, but qualitatively it was clear that, as with codon 12 mutations, both mutant and wild-type genes were expressed.

Control tumour tissues. Analysis of the expression of codon 12 mutant $\mathrm{Ki}$-ras in 2 xenografts showed values that covered the same range as the primary tumours: both mutant and wild-type alleles were expressed in both xenografts, one in near stoichiometric equivalence, the other with the mutant in excess by around 70\% (Fig. 3B and Table I). As expected, the three carcinomas without $\mathrm{Ki}$-ras mutation showed only wild-type cDNA (Fig. 3A tracks 2,3,7). 

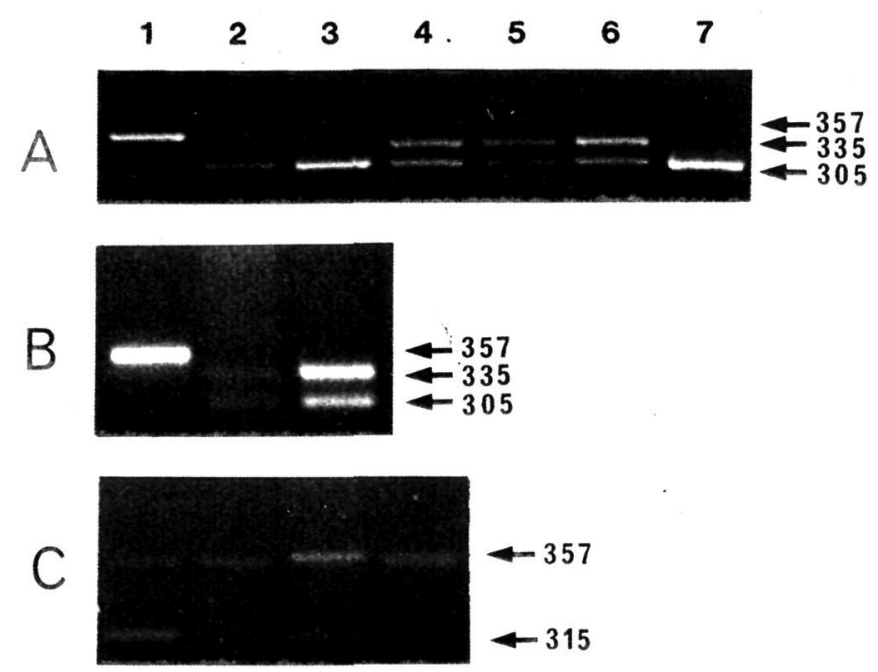

Figure 3. Results from the RFLP analysis. (A) codon 12 mutation analysis, lane1: undigested product, lanes 2, 3, 7: products from colon carcinomas with no codon 12 mutation after RFLP analysis, lanes 4, 5, 6: heterozygous products after RFLP analysis, (B) codon 12 xenograft analysis, lane 1: undigested product, lanes 2, 3: heterozygous mRNA Ki-ras products from xenografts after RFLP analysis, (C) codon 13 mutation detection in four heterozygous tumours.

Table I. Ki-ras codon 12 mutations detected by competitive RT-PCR-RFLP analysis in colon tumours and RFLP data from polymorphic sites close to or within $\mathrm{Ki}$-ras locus.

\begin{tabular}{|c|c|c|c|c|}
\hline Samples ${ }^{\mathrm{a}}$ & Mutation $^{\mathrm{b}}$ & $\begin{array}{l}\text { RNA ratio } \\
\text { (wt/mut) }\end{array}$ & RsaI & StuI \\
\hline
\end{tabular}

\begin{tabular}{lccccc}
\hline 1 & ASP12 & 0.66 & & A2 & A1A2 \\
2 & SER12 & 0.95 & & A2 & A1A2 \\
3 & ASP12 & 0.61 & A1 & A1A2 & \\
4 & ASP12 & 0.77 & A1 & A1 & A1 \\
5 & ALA12 & 0.86 & A1 & A1A2 & \\
6 & VAL12 & 0.88 & & & \\
7 & VAL12 & 0.68 & & & \\
8 & ASP12 & 0.57 & & A1 & A1A2 \\
9 & ASP12 & 0.61 & A1 & A2 & A2 \\
Xen 1 & VAL12 & 0.98 & & & \\
Xen 2 & VAL12 & 0.59 & & & \\
\hline
\end{tabular}

${ }^{\mathrm{a}}$ Xen=Xenograft tumours; ${ }^{\mathrm{b}}$ codon 12 amino acid substitutions; $\mathrm{A} 1=$ allele $1 ; \mathrm{A} 2=$ allele 2 .

RFLP analysis for loss of heterozygosity at the Ki-ras locus. Five of the 9 patients with carcinomas bearing codon 12 mutations were informative at polymorphic sites close to or within $\mathrm{Ki}-\operatorname{ras} 2$ (Table I). In every case, including 3 carcinomas in which the ratio of wild-type to mutant transcript was less than 0.67 , both alleles were clearly present within the tumour, apparently in approximately equal amounts. Thus there was no evidence for loss of heterozygosity at the $\mathrm{Ki}$-ras locus to account for the differences in expression between the Ki-ras alleles described above.

\section{Discussion}

We have described a quantitative RT-PCR method capable of discriminating mutant from wild-type Ki-ras transcripts in human tumour tissues. In this method, the ratio of the two species of transcript is a direct linear function of the ratio of their amplified, reverse-transcribed cDNAs. We attribute the simplicity of this relationship to the fact that no correction is required to match the efficiencies of synthesis of the mutant and wild-type products: during both reverse transcription and the polymerase chain reaction, synthesis of both proceeds within the same reaction vessel from the same primers, and PCR products are of identical length. Initially we were concerned that the relationship between RNA transcript and amplified cDNA might be significantly distorted by the extent of heteroduplex formation, since this could influence the kinetics of denaturation and reannealing. This may have been minimised by the relatively low number of cycles used.

The results show that mutant $\mathrm{Ki}-$ ras, if present in colorectal carcinoma DNA, is invariably expressed. Expression of wild-type Ki-ras never significantly exceeded that of the mutant, but often was substantially less. Loss of heterozygosity at the $\mathrm{Ki}$-ras locus is unlikely to be the explanation for this preferential expression of the mutated $\mathrm{Ki}$-ras allele, since a wild-type $\mathrm{Ki}$-ras allele was present together with the mutant allele, in every case where this could be ascertained. Moreover, $\mathrm{LOH}$ involving chromosome $12 p$ is one of the rarest defects documented in allelotypes of large series of human colorectal carcinomas (19), although selective loss of wild-type $\mathrm{Ki}$-ras has been documented in a small number of cases (20). The data from the cases presented here therefore point to the conclusion that mutated $\mathrm{Ki}$-ras genes, when present in colorectal carcinoma cells, tend to be expressed more than the wild-type genes by virtue of a transcriptional or post-transcriptional mechanism.

Quantitative analysis of data gathered from authentic tumour tissue, as here, is often uncertain because of the unknown extent to which intra-tumoral stroma contributes wild-type products to the tumour extracts. Excess stromal RNA would have increased towards unity the ratio of wildtype transcript to mutant, however, whereas the majority of the tumours studied here showed ratios substantially less than unity. Further, the ratio of wild-type to mutant transcripts in the xenografted tumours, in which the stromal component is negligible, covered the same range of values as in authentic primary tumours.

Many previous studies on a variety of animal and human tissues have indicated that mutational activation of ras genes is frequently an early event in the evolution of tumours (1,5$7,21)$. There is evidence that ras mutations may be influential at later stages of tumour progression also $(22,23)$. In experiments in which mutant ras genes are selectively inactivated by specific recombination events, the pre-existing tumour phenotype reverts to a more normal form (23), indicating that mutated ras genes are necessary, in these cells at any rate, for the maintence of malignant behaviour. On the other hand, the mere possession of a mutated ras gene is not sufficient for malignant transformation of some cell types $(5,6,12,25)$. Factors limiting its transforming potency appear to include its level of expression and that of any wild-type ras gene in the same cell. We interpret the data presented 
here to imply that expression of the Ki-ras oncogene may confer some survivorship or growth advantage upon tumour cells even in well-established tumours. In contrast, expression of the wild-type transcript may be diminished, because it is unnecessary for, or limiting to growth. It will be of interest to determine whether these early results are repeated in larger series of cases, and in particular whether the ratio of wild-type to mutant transcript differs between carcinomas and adenomas.

\section{References}

1. Spandidos DA and Anderson MLM: Oncogenes and oncosupressor genes: their involvement in cancer. J Pathol 157: 1-10, 1989.

2. Spandidos DA (Ed): Ras Oncogenes. Plenum Press, New York, London, pp1-323, 1989.

3. Fearon ER and Vogelstein B: A genetic model for colorectal tumorigenesis. Cell 61: 759-767, 1990.

4. Ashton-Rickardt PG, Wyllie AH, Bird CC, Dunlop MG, Steel CM, Morris RG, Piris J, Romanowski P, Wood R, White R and Nakamura Y: MCC, a candidate familial polyposis gene in 5q.21, shows frequent allele loss in colorectal and lung cancer. Oncogene 6: 1881-1886, 1991.

5. Aguilar-Cordova E, Strange R, Young LJT, Billy HT, Gumerlock PH and Cardiff RD: Viral Ha-ras mediated mammary tumor progression. Oncogene 6: 1601-1607, 1991

6. Strange R, Aguilar-Cordova E, Young LJT, Billy HT, Dandekar S and Cardiff RD: Harvey-ras mediated neoplastic development in the mouse mammary gland. Oncogene 4: 309-315, 1989.

7. Miyamoto S, Sukumar S, Guzman RC, Osborn RC and Nnandi S: Transforming c-Ki-ras mutation is a preneoplastic event in mouse mammary carcinogenesis. Mol Cell Biol 10: 1593-1599, 1990.

8. Brown K, Buchmann A and Balmain A: Carcinogen-induced mutations in the mouse $\mathrm{c}-\mathrm{H}$-ras gene provide evidence of multiple pathways for tumour progression. Proc Natl Acad Sci USA 87: 538-542, 1990.

9. Bremmer R and Balmain A: Genetic changes in skin tumor progression: correlation between presence of a mutant ras gene and loss of heterozygosity on mouse chromosome 7. Cell 61: 407-417, 1990.

10. Buchmann A, Ruggeri B, Klein-Szanto AJP and Balmain A: Progression of squamous carcinoma cells to spindle carcinomas of mouse skin is associated with an imbalance of $\mathrm{H}$-ras alleles on chromosome 7. Cancer Res 51: 4097-4101, 1990.

11. Winter E, Yamamoto F, Almoguera C and Perucho M: A method to detect and characterize point mutations in transcribed genes: amplification and overexpression of the mutated c-Ki-ras allele in human tumor cells. Proc Natl Acad Sci USA 82: 7575$7579,1985$.
12. Finney RE and Bishop JM: Predisposition to neoplastic transformation caused by gene replacement of $\mathrm{H}$-ras 1 . Science 260: 1524-1527, 1993.

13. Gilliland G, Perrin S, Blanchard K and Bunn HF: Analysis of cytokine mRNA and DNA: detection and quantitation by competitive polymerase chain reaction. Proc Natl Acad Sci USA 87: 2725-2729, 1990.

14. Siebert PD and Larrick JW: Competitive PCR. Nature 359: $557-$ $558,1992$.

15. Jiang W, Kahn SM, Guillen JG, Lu SH and Weinstein IB: Rapid detection of ras oncogenes in human tumors: applications to colon, esophageal and gastric cancer. Oncogene 4: 923-928, 1989.

16. McQueen HA, Wyllie AH, Piris J, Foster E and Bird CC: Stability of critical genetic lesions in human colorectal carcinoma xenografts. Br J Cancer 63: 94-96, 1991.

17. Heighway J: RsaI polymorphism in c-Ki-ras. Nucl Acids Res 19: $968,1991$.

18. Heighway J: Primers for detection of StuI and BstXI polymorphisms in a fragment co-amplified with c-Ki-ras2 (KRAS2). Nucleic Acids Res 19: 3162, 1991.

19. Vogelstein B, Fearon ER, Kern S, Hamilton SR, Preisinger CC, Nakamura Y and White R: Allelotype of colorectal carcinomas. Science 244: 207-211, 1989.

20. Shibata D, Schaeffer J, Li Z-H, Capella G and Perucho M: Genetic heterogeneity of the Ki-ras locus in colorectal adenomas but not in adenocarcinomas. $J$ Natl Cancer Inst 85: 1058-1063, 1993.

21. Nuzum EO, Malkinson AM and Beer DV: Specific Ki-ras codon 61 mutations may determine the development of urethaninduced mouse lung adenomas or adenocarcinomas. Mol Carcinog 3: 287-295, 1990.

22. Gallick GE, Kurzrock R, Kloetzer WS, Arlinghaus RB and Gutterman JU: Expression of p21 ras in human primary and metastatic tumors. Proc Natl Acad Sci USA 82:1795-1798, 1984.

23. Williams ARW, Piris J, Spandidos DA and Wyllie AH: Immunohistochemical detection of ras oncogene p21 product in an experimental tumour and in human colorectal neoplasms. $\mathrm{Br}$ J Cancer 52: 687-693, 1985.

24. Shirasawa S, Furuse M, Yokoyama N and Sasazuki T: Altered growth of human colon cancer cell lines disrupted at activated Ki-ras. Science 260: 85-88, 1993.

25. Spandidos DA, Frame M and Wilkie NM: Expression of the normal H-rasl gene can suppress the transformed and tumorigenic phenotypes induced by mutant ras genes. Anticancer Res 10: 1543-1554, 1990. 